Journal of Accident and Emergency Medicine 1995 $12,52-54$
Correspondence: Rachel Hartrey, Registrar, Anaesthetic Department, Great Ormond Street Hospital, London WC1N 3JH, UK

\title{
Pharyngeal trauma as a result of blind finger sweeps in the choking child
}

\author{
R. HARTREY \& R.M. BINGHAM
}

Great Ormond Street Hospital for Children NHS Trust, Great Ormond Street, London

\section{SUMMARY}

We present a case report to highlight the risk of pharyngeal trauma, as a result of blind finger sweeps in the choking infant.

Key words: foreign body, oropharynx.

\section{INTRODUCTION}

In their guidelines for paediatric life support, both the European Resuscitation Council ${ }^{1}$ and American Heart Association ${ }^{2}$ stress that blind finger sweeps of the pharynx should not be performed in the choking child. The primary reason given for this is the risk of pushing a foreign body (FB) deeper into the airway, and impacting it at the level of the cricoid cartilage.

We would like to highlight a further problem with this manoeuvre, the potential for damage to the pharyngeal mucosa.

\section{CASE HISTORY}

A 9-week-old, $4.9 \mathrm{~kg}$ baby girl with marked respiratory distress, was transferred to Great Ormond Street hospital under the care of the Ear, Nose and Throat (ENT) surgeons. She had been admitted to a local hospital the night before, with a history of choking on a paper tissue.

She was the first born of 36-week gestation twins and had recently been unwell with an upper respiratory tract infection. On the night of admission her father had been wiping her face with a tissue after she had vomited part of her bottled milk feed. Whilst still cradling the baby in his lap, he fell asleep with the tissue wrapped around his finger, but suddenly awoke to find her choking and part of the tissue in her mouth. Attempts were made to remove the tissue with a finger, but this only worsened her condition. She was then placed in the head down position and her back slapped several times, which resulted in a cry and enabled the father to remove the tissue from the mouth. Although her breathing was much improved at this stage, she remained very pale, which prompted her mother to call for an ambulance.

On arrival in the hospital she looked pale and had mild stridor. There was a mucopurulent discharge from her nose and she was tachypnoeic with a respiratory rate of 70 breaths $\mathrm{min}^{-1}$. Auscultation of the chest revealed bilateral crepitations and slightly reduced breath sounds on the right. Inspection of the mouth revealed some blood and a tear of the soft palate. Twenty millilitres of $4.5 \%$ albumin solution was given intravenously and antibiotics commenced.

During the night her respiratory distress worsened, requiring $50 \%$ head box oxygen to maintain saturations of $90 \%$. A full septic screen was performed and a chest radiograph revealed a slightly hyperinflated right lung. Thus she was transferred the following day with a presumed diagnosis of an aspirated FB.

Following atropine premedication, a rigid pharyngoscopy and laryngobronchoscopy was performed under halothane and oxygen anaesthesia with topical lignocaine spray.

Pharyngoscopy revealed a laceration of the right tonsil and pharyngeal mucosa extending down to the mid pyriform fossa (Fig. 1). There was pooling of saliva and extensive slough over the area, but no abscess or FB visible. The supraglottic region was also oedematous. Mucopurulent secretions were aspirated from the left bronchi on bronchoscopy, but again no FB could be seen.

At the end of the procedure the bronchoscope was removed, halothane discontinued and $100 \%$ oxygen given via a face mask. During and after the procedure the skin of the baby felt cool and had a mottled appearance, despite the maintenance of a warm environment. She was tachypnoeic and had marked subcostal recession with an oxygen 
Pharyngeal trauma in the choking child
Fig. 1. Right pharyngeal mucosal tear with extensive slough. (A), right arytenoid (B), mucosal tear with slough.

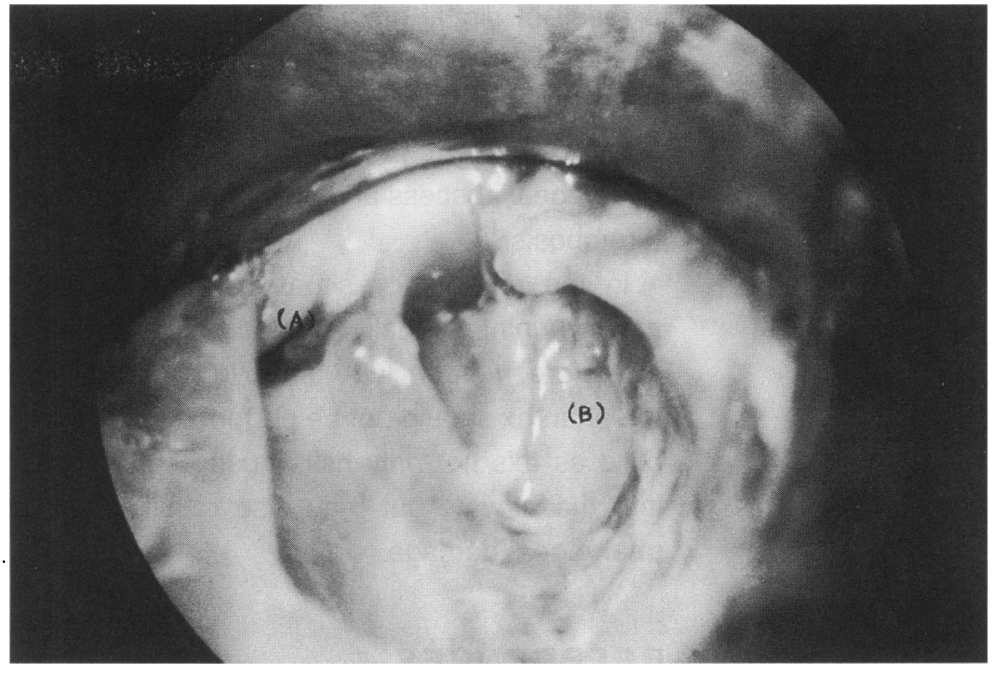

saturation of $94 \%$. Forty millilitres of $4.5 \%$ albumin solution was given intravenously, resulting in an improvement in the skin appearance and respiratory pattern. It was decided to transfer her to the intensive care unit for closer observation and treatment of presumed sepsis.

She responded quickly to intravenous fluid and antibiotic therapy over the course of $12 \mathrm{~h}$, and at this time no longer required oxygen. Blood and cerebrospinal fluid cultures were subsequently negative for bacterial and viral growth but two sputum samples gave a scanty growth of Escherichia coli and Staphylococcus aureus.

Nasogastric feeding was commenced on the first postoperative day and continued for 1 week. She was transferred to the ward after 2 days and discharged home 5 days later.

\section{DISCUSSION}

In the United States approximately $\mathbf{3 0 0 0}$ deaths a year are caused by choking, ${ }^{3} 10 \%$ of which are children. ${ }^{4}$ Recent data from the Office of Population Censuses and Surveys of Great Britain show a total of 349 deaths as a result of FB obstruction of the pharynx, larynx and bronchi during the year of $1992 .^{5}$ Twenty-eight of these deaths occurred in children of less than 15 years of age.

As recommended by the European Resuscitation Council and American Heart Association, if a FB aspiration is witnessed or strongly suspected, then the rescuer should encourage the child to continue coughing as long as the cough is forceful. Relief of the obstruction should be attempted only found respiratory difficulty, or if the victim loses consciousness.

In the infant a combination of back blows and chest thrusts are preferred. Abdominal thrusts should be avoided for fear that they may damage the large and unprotected liver, but in older children they may be used if chest thrusts and back blows are unsuccessful.

Since the introduction of these guidelines there has been a $20 \%$ reduction in mortality related to choking, as recorded by the National Satety Council in the United States of America. ${ }^{6}$

The first significant work on airway obstruction was carried out by Samuel D. Gross ${ }^{7}$ in 1854. Based upon the critical analysis of 200 cases, he concluded that a victim of an aspirated FB should never be finger probed, because of the risk of increasing the impaction. Following on from this Chevalier Jackson ${ }^{8}$ reviewed 6000 case studies of choking that occurred between 1912 and 1973, and again concluded that the rescuer should never probe the pharynx. However, if a foreign body is clearly visible in the mouth, it may be removed carefully with forceps or a hooked finger.

The risk of pharyngeal trauma as a result of finger probing a FB, has not been widely reported in the literature, and only rarely appears in relation to incidents of child abuse..$^{9,20}$ In fact pharyngeal trauma of any kind in the infant and child is either uncommon or under reported, probably the latter considering the vulnerability of the child's mucous membranes. Pharyngeal trauma has been recorded in newborns as a result of nasogastric and endotracheal tube insertions. ${ }^{11}$ There are also several reports of considerable pharyngeal damage as 
R. Hartrey \&

R.M. Bingham a result of digital manipulation as used by an obstetrician to deliver the after coming head of a breech baby. ${ }^{12}$ Complications from pharyngeal trauma are rare but include mediastinitis, retropharyngeal abscess and even internal carotid artery thrombosis. ${ }^{13}$

In the emergency situation considerable force may be unintentionally exerted through the fingers. Therefore, we conclude that blind finger sweeps of the pharynx should not be performed in the choking child as this not only risks pushing the FB further into the airway, but may also result in extensive pharyngeal damage.

\section{REFERENCES}

1. Paediatric Life Support Working Party of the European Resuscitation Council. (1994) Guidelines for paediatric life support. British Medical Journal 308, 1349-1355.

2. Emergency Cardiac Care Committee and Subcommittees, American Heart Association. (1992) Guidelines for cardiopulmonary resuscitation and emergency cardiac care. Part V. Pediatric basic life support. Journal of the American Medical Association 268(16), 2251-2261.

3. Day R.L. (1986) Comments on first aid for victims of choking. An extension of remarks made upon receiving the 1986 Howland Award. Pediatric Research 20(10), 1013-1014.
4. Committee on Pediatric Emergency Medicine. (1993) First Aid for the Choking Child. Pediatrics 92(3), 477-479.

5. Office of Population Censuses and Surveys. (1992) Mortality Statistics. HMSO, London.

6. National Safety Council. (1984) How people died in home accidents: 1983. Accident Facts, 6-7.

7. Gross S.D. (1854) A Practical Treatise on Foreign Bodies in the Air Passages. Blanchard \& Lea, Philadelphia.

8. Jackson C.L. (1973) Foreign bodies in the air and food passages. In: Maloney W.H. (ed.) Otolaryngology, Vol 5. Harper \& Row, New York.

9. Nolte K.B. (1993) Esophageal foreign bodies as child abuse. Potential fatal mechanisms. American Journal of Forensic Medicine and Pathology 14(4), 323-326.

10. McDowell H.P. \& Fielding D.W. (1984) Traumatic perforation of the hypopharynx - an unusual form of abuse. Archives of Disease in Childhood 59, 888889.

11. Touloukian R.J., Beardsley G.P., Ablow R.C. \& Effman E.L. (1977) Traumatic perforation of the pharynx in the newborn. Pediatrics 59, 1019-1022.

12. Girdany B.R., Sieber W.K. \& Osman M.Z. (1969) Traumatic pseudodiverticulums of the pharynx in newborn infants. New England Journal of Medicine 280, 237.

13. Kosakii H., Nakamura N. \& Toriyama Y. (1992) Penetrating injuries to the oropharynx. Journal of Laryngology and Otology 106, 813-816. 